\title{
Design and Development of Prosthetic Hand Controlled by Wireless Gestures for Differently-Able People
}

\author{
G.Shanmugasundar, Dharanidharan M, Vishwa D, Jayaprakash A, Abimanyu P
}

\begin{abstract}
This paper focuses on the design and development of Prosthetic hand to help differently-able people who lost their hands due to accidents and diseases. Our research purpose is to develop a master and slave robotic system that will be a substitute for the lost hand to do the day-to-day activities of a person. The person has to wear smart gloves in the hand to do gesture action. The gloves will able to transfer the hand gestures of differently-able people to react suitably and move the hand gripper (which contains spring coils similar to bones in human hand) based on the data from smart gloves. The methodology behind this research is that the analog signals produced in the flex sensor due to the gesture action are transferred to the servo motors to do a similar action in the $3 D$ printed prosthetic hand through the Wi-Fi module. This research project involves two Arduino microcontrollers for communicating and controlling applications in both master and slave sections. A number of flex sensors are placed in the glove to get readings of the motion of human fingers and it is transmitted through the Wi-Fi module by using the Arduino microcontroller. The transmitted signals are received by the Wi-Fi module in the slave section through the Arduino microcontroller and further uses this signal to control various servo motors and it controls the slave robotic hand by using the ropes attached between the servo motor and $3 D$ printed parts. Not only for differently-able people, but the enlarged model of this project can also be used in industries to handle hazardous, harmful, high temperatures and harmful things.
\end{abstract}

Keywords : Arduino, Flex sensor, Prosthetics, Robotic hand

\section{INTRODUCTION}

In the 21st century, people want to obtain a healthy and high-quality lifestyle. At this point, robots will alter our daily

Revised Manuscript Received on April 13, 2020.

* Correspondence Author

Shanmugasundar.G*, Department of Mechanical Engineering, Sri Sai Ram Institute of Technology, Chennai, Tamil Nadu, India. Email:shanmugasundar.mech@sairamit.edu.in

Dharanidharan M, Department of Mechanical Engineering, Sri Sai Ram Institute of Technology, Chennai, Tamil Nadu, India. Email: dharani.dd92@gmail.com

Vishwa D, Department of Mechanical Engineering, Sri Sai Ram Institute of Technology, Chennai, Tamil Nadu, India. $\quad$ Email: vishwad08@gmail.com

Jayaprakash A, Department of Mechanical Engineering, Sri Sai Ram Institute of Technology, Chennai, Tamil Nadu, India. Email: i7me049@sairamtap.edu.in

Abimanyu P, Department of Mechanical Engineering, Sri Sai Ram Institute of Technology, Chennai, Tamil Nadu, India. $\quad$ Email:

i7me099@sairamtap.edu.in

(C) The Authors. Published by Blue Eyes Intelligence Engineering and Sciences Publication (BEIESP). This is an open access article under the CC BY-NC-ND license (http://creativecommons.org/licenses/by-nc-nd/4.0/) lives at least by being assigned such as helpers, servants, and assistants to surgery operations in the medical area, helpers in any search. Robotics is a multidisciplinary scientific field that is combined some systematic disciplines such as mechanical, computer, industrial, electrical and electronics engineering disciplines. The word "Prosthetics" refers to the artificially designed part of the body. In recent years, robotics has a great influence over the prosthetics area. The hands which are one of the most vital elements of our human body are replicated as a robotic system. It is one of the most complicated components of our human body which acts as an input (tactile sensing) and output (physical work) device to human beings. Several studies are being carried out in the scientific and engineering discipline to develop a prosthetic hand with improved abilities. This research aims to assist the differently-able people in providing them with an enhanced version of prosthetics that is economical and affordable. The robotic hand research has grown considerably mainly in the improvement of the robotic hand beginning from the development of research hand to the industrial hand. The prosthetic hand which is available in the market with excellent features may be very expensive and certain people can only buy it. This research aims to develop a low-cost robotic hand by using readily available and broadly used mechatronics components. The hand has to be easy to fabricate and by using the available components in the market. The prosthetic hand must carry out the day-to-day activities like taking, holding and placing an item and giving hand signs.

\section{APPLICATIONS}

\section{A. Medical Applications}

It is a prosthetic hand that can be used as a substitute for the hand which was lost by them due to the accidents that will help the differently-able people to do their day-to-day activities on their own and they need not depend on anybody.

\section{B. Industrial Applications}

The enlarged model of this robotic hand can also be used in the industries to handle hazardous, radioactive, high temperatures and harmful things which are difficult to be handled by the industrial workers.

\section{Military Applications}

Lots of people are being injured during the disposal of bombs and land mines.

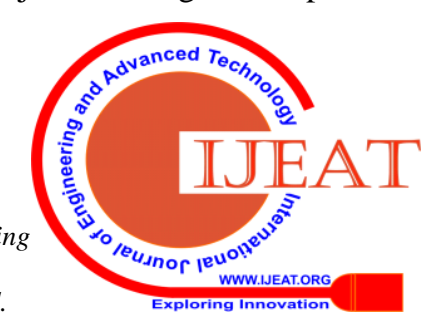


So the system has this kind of robotic hand that can be used to prevent those injuries.

\section{Recreational use}

This robotic hand can also be used for some recreational purposes such as playing items for children and to handle heavy and bulky objects.

\section{OBJECTIVES}

- It is very affordable as compared to the present robotic hand due to its low cost.

- It is easily portable and can be carried out anywhere easily.

- Lightweight 3D printed parts make it easy for the differently-able persons to carry with them.

- It has a lot of chances for modification according to their requirements.

- Its workings are often be made fully automatic and can be controlled through Wi-Fi.

\section{LITERATURE REVIEW}

Modern researches supported robotics hand designs are found out in several research centres on the planet since the '80s. In 1986, the primary prosthetic hand developed by the Utah University and MIT consisted of three fingers and a thumb. It had been used to observe the mobility of machines used for construction purposes.

At the beginning of the '90s, robotics started to point out a few differences with the substances made and consequently the NASA Johnson space center made a replacement robot hand which includes sub-units. The primary set can be used for manipulation as it has the capacity of mobility and therefore the other was a group of gradually gripping during the motion of an object.

The replacement robotics device was introduced by Byoung $\mathrm{k}$ et al. The research wrapped to the present time has focused on simplicity, noise reduction, cheap, lightness, low electricity, human fitness, and controllable. A robot hand that resembles the human hand with its 24-degree of free mobility in 2006 was developed by a leading robot manufacturer, Shadow robotic company.

Zajdlik et al. made it possible to use the wavelet theory and the artificial neural networks on the EMG signals in his observation. In later, the capacitive sensors have been broadly used in the robotic hands. Kappassov et al. designed a robotic hand with highly sensitive capacitive, optical, barometric, piezoelectric and quantum effect sensors.

Therefore, many types of research in this discipline are being executed in the medical and engineering fields. Our research motive is to develop a software and hardware system, which allows remote manipulation of the finger movements and it is controlled remotely by the humans wearing the master gloves. The most unique of the system is that the angle resistance relationship is acquired by using the flex sensor for detecting the human finger movement and it's controlled using a microcontroller through the Wi-Fi module.

\section{MECHANICAL SETUP}

The mechanical setup involves the process of designing, prototyping, manufacturing and assembling of various components of the prosthetic hand. Each of the components is explained briefly in the subsequent sections.

The design of the hand is drawn using PTC Creo Parametric. The drawn design as shown in Fig. 1 and Fig. 2 are $3 \mathrm{D}$ printed and assembled to produce the entire component. In our design, we have used springs to join different segments of the fingers and the fingers to the hand. It acts similar to the bone in the human hand and it is flexible and easily replicates the hand motion. The edges of the fingers are connected to the servo motor by using nylon\stringlbraid wires.

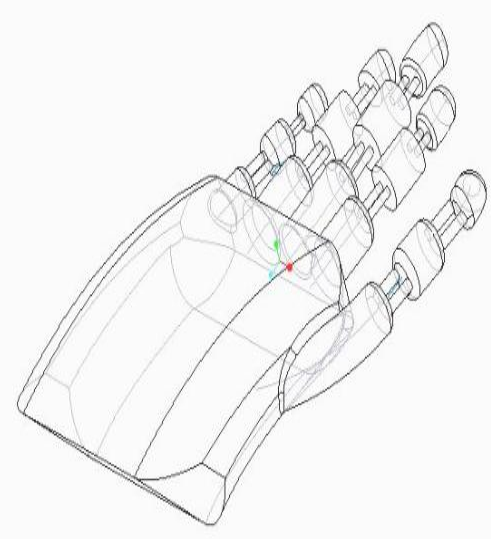

Fig. 1. CAD Design of Prosthetic hand

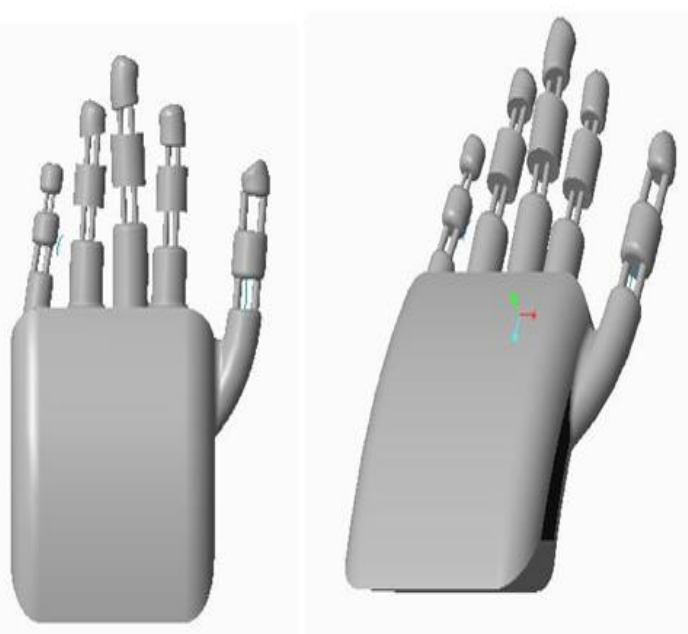

Fig. 2. CAD Design of Prosthetic hand

\section{DESIGN CALCULATION}

\section{A. Servo Motor}

Force exerted by the weight of hand and spring $=400$ to 450 grams (based on the size of finger)

$$
=0.40 \text { to } 0.45 \mathrm{~kg}
$$

$$
=
$$

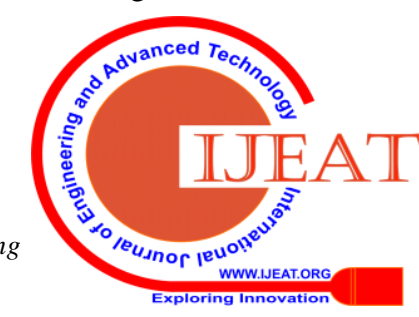


$0.45 \mathrm{~kg}$ (taking maximum value)

Force, $\mathrm{F}=0.45 \times 9.81=4.42 \mathrm{~N}$

Length of side shaft attached with servo motor $=2.2 \mathrm{~cm}$

Torque $=$ Force $\mathrm{X}$ length $=4.42 \times 2.2$

Torque $=9.724 \mathrm{~N}-\mathrm{cm}$

Torque $=9.724 / 9.81=0.92 \mathrm{Kg}-\mathrm{cm}$

By standards, select servo motor having torque $1.5 \mathrm{Kg}-\mathrm{cm}$ of the following specifications:

Voltage $=4.8 \mathrm{~V}$

Angle of rotation $=0$ to 180 degrees

Speed $=0.2 \mathrm{~s} / 60^{\circ}$

Pulse cycle $=1 \mathrm{~ms}$

B. Flex Sensor

Height $=0.43 \mathrm{~mm}(0.017$ ')

Flat Resistance $=10 \mathrm{~K}$ ohms

Bend Resistance $=60 \mathrm{~K}$ to $110 \mathrm{~K}$ ohms

Resistance Tolerance $=30 \%$

Rating $=0.50$ Watts continuous

\section{Arduino}

Type: Arduino UNO (due to compact size)

Modulation: ATmega 328P

Voltage: $5 \mathrm{~V}$

\section{CIRCUIT CONNECTION}

The prosthetic hand consists of the transmitter section and receiver section. The transmitter section has to be worn by the user and the receiver section has been connected to the prosthetic hand. The transmitter section consists of five flex sensors, Arduino microcontroller, Wi-Fi module, battery and they are mounted on a glove that has to be worn by the user. The receiver section consists of five servo motors, Arduino microcontroller, Wi-Fi module, battery and they are connected to the 3D printed prosthetic hand. The Fig. 3. Shows the connection of the transmitter section and Fig. 4. Shows the connection of the receiver section.

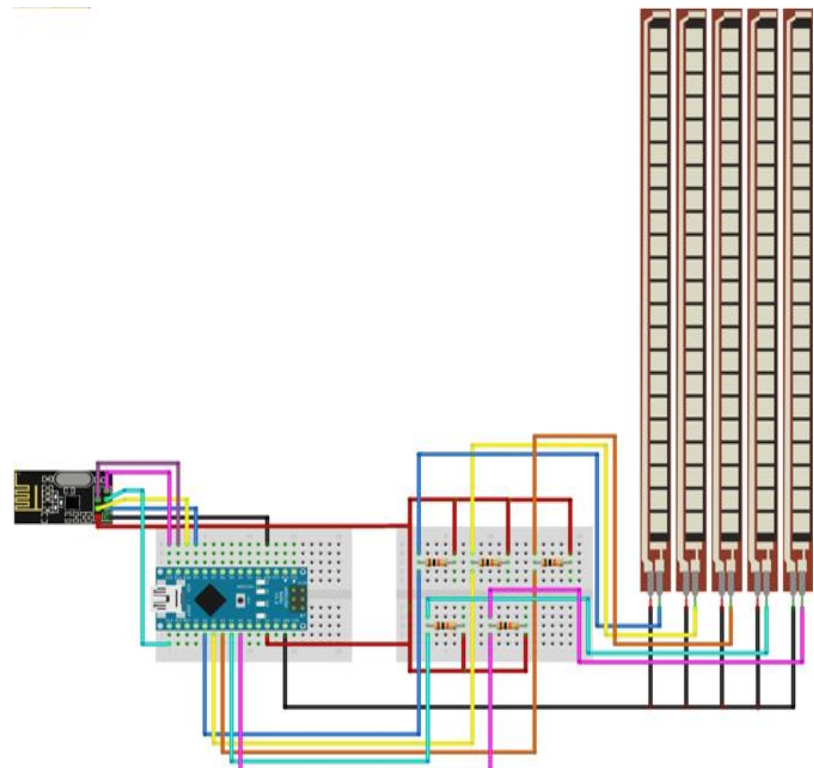

Fig. 3. Transmitter section

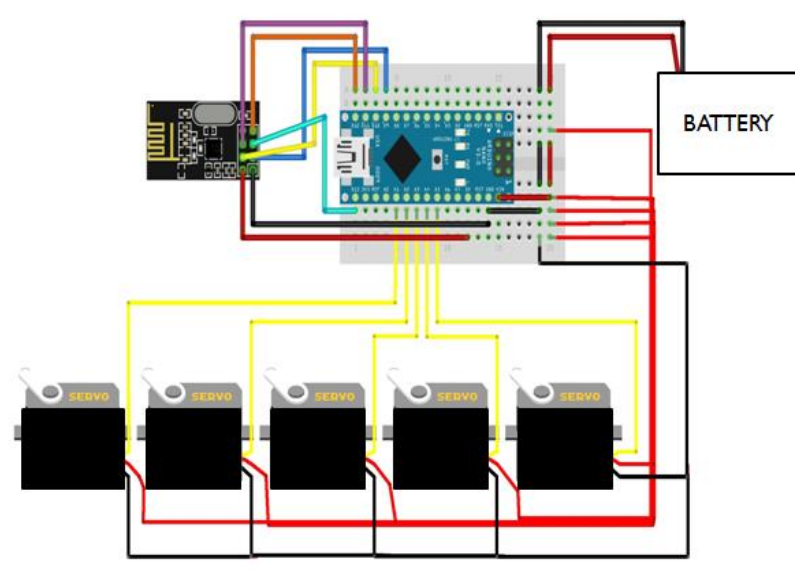

Fig. 4. Receiver section

VIII. COMPONENT REQUIREMENT

TABLE. 1. COMPONENT REQUIREMENT

\begin{tabular}{|c|l|c|}
\hline S.NO. & \multicolumn{1}{|c|}{ PART NAME } & QUANTITY \\
\hline 1. & Arduino UNO & 2 \\
\hline 2. & Servo Motor & 5 \\
\hline 3. & 4.5 inch flex sensor & 5 \\
\hline 4. & Wi-Fi module & 2 \\
\hline 5. & Breadboardd & 2 \\
\hline 6. & Hand Gloves & 1 \\
\hline 7. & Spring coil & 5 \\
\hline 8. & Nylon wire/string & 5 \\
\hline 9. & Jumper wires & - \\
\hline 10. & Battery & 2 \\
\hline 11. & 3D Printed Parts & - \\
\hline & & \\
\hline
\end{tabular}

The above Table 1 . shows the detailed cost estimation for the research work. The cost is mentioned in Indian rupees in the above table.

\section{WORKING PROCEDURE AND RESULT}

When the fingers of the hand bend, the flex sensor attached with the transmitter section of the hand gloves generates an analog signal which is transmitted to the receiver section through a Wi-Fi module connected with the Arduino microcontroller. The receiver section of the prosthetic hand receives the signal from the transmitter using the $\mathrm{Wi}-\mathrm{Fi}$ module. The Arduino microcontroller at the receiver section processes and sends the digital signals to the respective servo motor and the finger movements are replicated in the prosthetic hand. Fig. 5. Shows the working principle of our prosthetic hand.

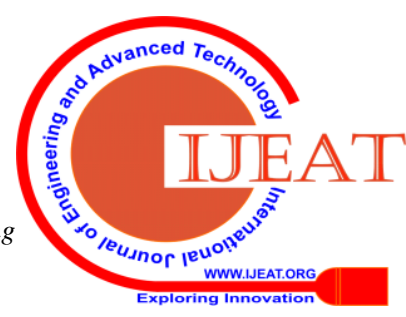


TRANSMITTER SECTION

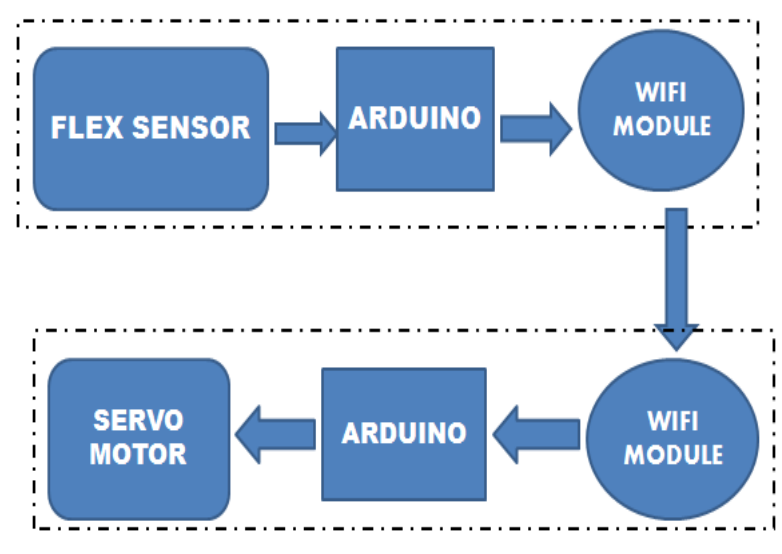

RECIEVER SECTION

Fig. 5. Working Procedure

\section{CONCLUSION}

This paper presents the design and development of prosthetic hand which is controlled by wireless gestures for differently-able people. This explains the concepts behind the mechanical design of prosthetic hand, flex sensor, Wi-Fi module and how the wireless movements get transformed into the movements of the prosthetic hand. Our project mainly aims to help people who lost their single hand by accidents or by birth. It helps them to do their day-to-day simple tasks and to live like an ordinary person. It can be not only used for physically challenged persons, and also used to handle hazardous, radioactive, toxic and high-temperature objects in the industries. It has a great scope in the market and many physically-challenged persons will be benefited.

\section{REFERENCES}

1. Shruthi k, "Low-Cost Prosthetic Hand using Flex Sensors and Servo Motors", in the International Journal of Engineering Research \& Technology (IJERT), 2018.

2. Belter JT, Segil JL, Dollar AM, Weir RF, "Mechanical design and performance specifications of anthropomorphic prosthetic hands: A review", J Rehabil Res Dev.;50(5):599-618, 2013.

3. Nicolas Gorges, Andreas J. Schmid, Dirk Gager, and Heinz Warn, "Grasping and Guiding a Human with a Humanoid Robot", 8th IEEE-RAS International Conference on Humanoid Robots, Daejeon, Korea, (2008).

4. Hannes Fillipi, "Wireless Teleoperation of Robotic Arms", Lulea University of Technology: Master Thesis, 2007.

5. Aditya Purkayastha, Akhil Devi Prasad, Arunav Bora, Akshay Kumar Gupta, Pankaj Singh, "Hand Gestures Controlled Robotic Arm”, Journal of International Academic Research For Multidisciplinary Impact Factor 1.393, ISSN: 2320-5083, Volume 2, Issue 4, May 2014.

6. D. J. Beebe, D. D. Denton, R. G. Radwin, and J. G. Webster, "A silicon-based tactile sensor for finger mounted applications," IEEE Trans. Biomed. Eng., vol. 45, pp. 151-159, Feb. 1998.

7. Freivalds, Andris. "Biomechanics of the Upper Limbs: Mechanics, Modeling and Musculoskeletal Injuries," vol. 16, n॰4. pages. 215-221.2004.

8. L. Pao and T. Speeter, "Transformation of Human Hand Positions for Robotic Hand Control," IEEE International Conference on Robotics and Automation, vol. 3, May 1989, pp. 1758-1763.

9. G. Shanmugasundar, R. Sivaramakrishnan, (2012), Modelling, Design and Static Analysis of Seven Degree of Freedom Articulated Inspection Robot “, Applied materials research, Vol. 655-657, pp 1053-1056.

10. G. Shanmugasundar, R. Sivaramakrishnan, "A Survey on Development of Inspection Robots: Kinematics Analysis, Workspace Simulation and Software Development", International Review Of Mechanical Engineering, 2012, Vol 6. N 7, pp. 1493-1507.

11. Lerman, K., Martinoli, A., and Galstyan, A., 2005, "A Review of Probabilistic Macroscopic Models for Swarm Robotic Systems,"
Proceedings of the 2004 International Conference Swarm Robotics, Santa Monica, CA, July 17, Springer, Berlin, Germany, pp. 143-152.

\section{AUTHORS PROFILE}

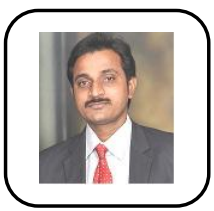

G.Shanmugasundar is working as an Associate Professor in the Mechanical Engineering Department, Sri Sai Ram Institute of Technology, Chennai-44. He has completed Ph.D. in the area of Designing of Inspection robot at Madras Institute of Technology, Anna University Chennai, Tamil Nadu. India. He obtained his Bachelor's degree in Mechanical Engineering from AVC Engineering College, Mailaduthurai, Tamil Nadu India. His research work includes the kinematic study, modeling and simulation and its application in the nuclear industry. He has a vast experience in teaching CAD/CAM, modern manufacturing systems, Special casting process, Manufacturing Technology, Mechatronics, Engineering Graphics, and Design Subjects. He has written a book on Computer-Aided Manufacturing. He has specialization in the areas of high-end softwares. He is contributing as a life member with ISTE, IEI, AMM and . He published More than 15 papers in many reputed journals.

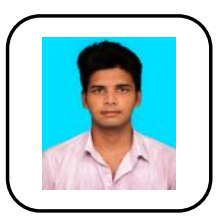

Dharanidharan $\mathbf{M}$ student at Department of Mechanical Engineering, Sri Sai Ram Institute of Technology, Chennai, Tamil Nadu, India. He is a proud member of SAE India, IEI, IEDC and ISTE. He has worked in various robotics application projects and done a wide range of research in that field. Also he has good experience in manufacturing engineering works which involves working in automated systems and robotic systems. He has attended many conferences and workshops in the robotics field. He participated in several Hackathon, paper presentations, orations, etc. He has good knowledge in the designing and manufacturing field and a fair amount of knowledge in $\mathrm{C}$ and Python programming.

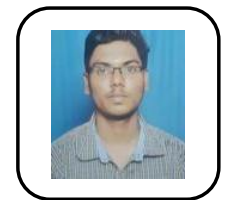

Vishwa D student at Department of Mechanical Engineering, Sri Sai Ram Institute of Technology, Chennai, Tamil Nadu, India. He is a proud member of SAE India, IEI, IEDC and ISTE. He has a wide robotics knowledge and done many researches in that field. He has done projects in the electric vehicle and attended workshops in that field. He has participated in many e-vehicle competitions, hackathons and paper presentations. He has a good knowledge in design, $\mathrm{C}$ and Python programming languages.

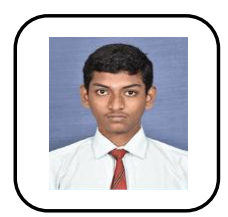

Jayaprakash A student at Department of Mechanical Engineering, Sri Sai Ram Institute of Technology, Chennai, Tamil Nadu, India. He is a proud member of SAE India, IEI and ISTE. He has a piece of good knowledge in the manufacturing field. He has attended various workshops and conferences. He has done various research projects in the robotics field.

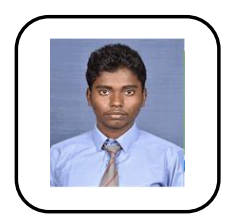

Abimanyu P student at Department of Mechanical Engineering, Sri Sai Ram Institute of Technology, Chennai, Tamil Nadu, India. He is a proud member of SAE India, IEI and ISTE. He has a wide robotics knowledge and done many researches in that field. He has attended various conferences and workshops in the robotics field.

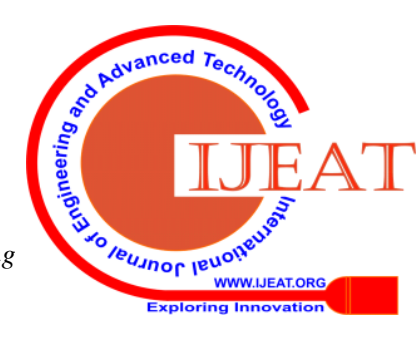

